\title{
Effect of tempering on microstructure and properties of Fe-Cr-B-Al alloy
}

\author{
J. Ju ${ }^{1}$, H.-G. Fu ${ }^{1 *}$, Z.-G. Xing ${ }^{2}$, Y.-P. Lei ${ }^{1}$ \\ ${ }^{1}$ School of Materials Science and Engineering, Beijing University of Technology, Beijing 100124, P. R. China \\ ${ }^{2}$ Engineering Research Center of Hebei for Abrasion Resistant Metal Matrix Composite, \\ Handan 056000, Hebei Province, P. R. China
}

Received 2 August 2016, received in revised form 24 March 2017, accepted 28 March 2017

\begin{abstract}
The effect of tempering on the microstructure, mechanical properties and wear resistance of cast $\mathrm{Fe}-10$ wt.\%Cr-1.5wt.\%B-2wt.\% Al (referred to as Fe-Cr-B-Al) alloy after quenching at $1100{ }^{\circ} \mathrm{C}$ has been investigated in the present study. The results show that microstructure of tempered $\mathrm{Fe}-\mathrm{Cr}-\mathrm{B}-\mathrm{Al}$ alloy consists of tempered martensite, massive ferrite and discontinuous eutectic borocarbide. With the increasing tempering temperature, the retained austenite is gradually transformed into martensite. When the tempering temperature is higher than $450^{\circ} \mathrm{C}$, the content of ferrite in the matrix increases gradually, however, the content of martensite decreases gradually. There was no significant change in the morphology of borocarbide. With the tempering time $(4-12 \mathrm{~h})$ and tempering cycle increasing, the content of ferrite in the matrix increases gradually. When the tempering temperature is lower than $450^{\circ} \mathrm{C}$, the hardness of Fe-Cr-B-Al alloy has no obvious change. With the increasing temperature, the hardness gradually decreases. The hardness of $\mathrm{Fe}-\mathrm{Cr}-\mathrm{B}-\mathrm{Al}$ alloy almost reaches the highest value after once tempering and decreases slightly after tempering for two or three cycles. With the extension of tempering time, it is beneficial to the precipitation of carbide, and the hardness of Fe-Cr-B-Al alloy increases gradually. When the tempering time is too long, the hardness begins to decrease. Fe-Cr-B-Al alloy has excellent wear resistance while quenching at $1100^{\circ} \mathrm{C}$ and tempering at $450^{\circ} \mathrm{C}$; the main wear mechanism is cutting wear and ploughing effect.
\end{abstract}

K e y words: Fe-Cr-B-Al alloy, tempering temperature, tempering time, microstructure, hardness, wear resistance

\section{Introduction}

Fe-Cr-Al alloy is a commonly used heat-resistant alloy, it is easy to form $\alpha-\mathrm{Al}_{2} \mathrm{O}_{3}$ film at high temperature, and it is one of metal materials with the best oxidation resistance above $1000^{\circ} \mathrm{C}[1,2]$. However, the $\mathrm{Al}_{2} \mathrm{O}_{3}$ film is easy to peel off during the thermal cycling process, which reduces the oxidation resistance of the alloy [2-4]. Fe-Cr-B alloy has better quenching hardenability, quenching hardness and wear resistance compared with conventional high chromium white cast iron $[5,6]$, but it has poor oxidation resistance at high temperatures. Aluminum is non-carbide and nonboride forming element. Aluminum entering into the metal base is expected to increase the matrix hardness and high-temperature strength, which can ensure carbides and borides solid phases provided with good support under high-temperature conditions, and give full play to the role of anti-wear solid phase. We developed the Fe-Cr-B-Al alloy which has high hardness and good oxidation resistance by adding aluminum in Fe-Cr-B alloy. It is expected to replace currently used common high-temperature wear-resistant metal materials $[7-11]$.

In the articles which have been consulted, many researchers pay more attention to the research on the microstructure and properties of Fe-Cr-Al or Fe-Cr-B alloy [12]. Only Ukraine Pokhmurs'ka et al. [13, 14] report that the arc spraying and laser cladding FeCr-B-Al coatings have excellent corrosion resistance. Heat treatment is the main factor that affects the microstructure and properties of Fe-Cr-B-Al alloy. Previ- 
Table 1. Designed chemical composition of Fe-10Cr$-1.5 \mathrm{~B}-2 \mathrm{Al}$ alloy (wt.\%)

\begin{tabular}{ccccccc}
\hline $\mathrm{Cr}$ & $\mathrm{Al}$ & $\mathrm{B}$ & $\mathrm{C}$ & $\mathrm{Si}$ & $\mathrm{Mn}$ & $\mathrm{Fe}$ \\
\hline 10.00 & 2.00 & 1.50 & 0.30 & 0.60 & 0.70 & Bal. \\
\hline
\end{tabular}

Ta b l e 2. Original chemical composition of Fe-10Cr-1.5B$-2 \mathrm{Al}$ alloy (wt.\%)

\begin{tabular}{ccccccc}
\hline $\mathrm{Cr}$ & $\mathrm{Al}$ & $\mathrm{B}$ & $\mathrm{C}$ & $\mathrm{Si}$ & $\mathrm{Mn}$ & $\mathrm{Fe}$ \\
\hline 9.75 & 2.05 & 1.47 & 0.31 & 0.84 & 0.92 & $\mathrm{Bal}$. \\
\hline
\end{tabular}

ous studies have found that adding the proper amount of chromium and boron can obtain borocarbides with high hardness so as to improve the wear resistance of the material $[15,16]$. Also, the microstructure of the matrix transformed into martensite after quenching at $1100^{\circ} \mathrm{C}$, which makes the hardness of $\mathrm{Fe}-\mathrm{Cr}-\mathrm{B}-\mathrm{Al}$ alloy increases significantly. However, the matrix is not stable and changes under appropriate conditions, which leads to change in the size and shape of the parts. To stabilize the structure, to eliminate the internal stress, to avoid deformation and crack, the effect of tempering on microstructure and mechanical properties of Fe-Cr-B-Al alloy has been investigated extensively in the present study, so as to determine the optimum heat treatment process and obtain the best overall performance. Above work can provide guidance for the development of Fe-Cr-B-Al alloy heat treatment process.

\section{Experimental procedure}

\subsection{Material preparation}

The investigated alloys were melted in a $10 \mathrm{Kg}$ vacuum induction melting furnace with charge materials of steel scrap, pure aluminum, Fe-63wt.\%Cr, Fe-20wt.\%B, Fe-75wt.\%Si and Fe-78wt.\%Mn. The liquid metal was subsequently super-heated to $1550^{\circ} \mathrm{C}$ and poured at $1450{ }^{\circ} \mathrm{C}$ into $\varnothing 80 \mathrm{~mm} \times 200 \mathrm{~mm}$ bars in cast iron mold, followed by air cooling to room temperature. The metallographic analysis of the specimens was all measured at the center of $\varnothing 80 \mathrm{~mm}$ cross section of the bars in the square of $15 \mathrm{~mm} \times 15 \mathrm{~mm}$. The samples were etched with $4 \%$ nital for optical microscopy examination. The designed chemical composition of Fe-Cr-B-Al alloy is listed in Table 1. The original composition of the investigated alloys was analyzed by X-ray fluorescence spectrometer, which is given in Table 2.

By consulting the literature data, we analyzed
Table 3. Process of heat treatment of samples

\begin{tabular}{cccc}
\hline \multirow{3}{*}{ Number } & \multicolumn{3}{c}{ Tempering } \\
\cline { 2 - 4 } & $\begin{array}{c}\text { Temperature } \\
\left({ }^{\circ} \mathrm{C}\right)\end{array}$ & $\begin{array}{c}\text { Holding time } \\
(\mathrm{min})\end{array}$ & Times \\
\hline $1 \#$ & 600 & 240 & 1 \\
$2 \#$ & 550 & 240 & 1 \\
$3 \#$ & 500 & 240 & 1 \\
$4 \#$ & 450 & 240 & 1 \\
$5 \#$ & 400 & 240 & 1 \\
$6 \#$ & 450 & 240 & 2 \\
$7 \#$ & 450 & 240 & 3 \\
$8 \#$ & 450 & 60 & 1 \\
$9 \#$ & 450 & 480 & 1 \\
$10 \#$ & 450 & 720 & 1 \\
\hline
\end{tabular}

the heat treatment process of $\mathrm{Fe}-\mathrm{Cr}-\mathrm{B}-\mathrm{Al}$ alloy. In the preliminary test, the samples were quenched with water at different temperatures (1000, 1050, 1100 and $1150{ }^{\circ} \mathrm{C}$, respectively) for $1 \mathrm{~h}$. The microstructure, hardness and wear resistance of quenched samples were measured and compared. The sample which was quenched at $1100^{\circ} \mathrm{C}$ was selected as the test material because its hardness reached 65.4 HRC. The microstructure of matrix is martensite and is uniform. The specific tempering process is shown in Table 3 .

\subsection{Experimental analysis}

The micro-analysis examination of the specimens was carried out by using an optical microscope (OM), $\mathrm{X}$-ray diffraction (XRD), scanning electron microscope (SEM). The SEM used was an S-3400 microscope (Japan) with Energy Dispersive Spectrometer (EDS) attached. XRD was performed on a SHIMADZU Japan XRD-7000 diffractometer with $\mathrm{Cu} \mathrm{K} \alpha$ radiation coupling continuous scanning at $40 \mathrm{kV}$ and $200 \mathrm{~mA}$ as an X-ray source. The specimen was scanned in the angular $2 \theta$ ranging from $10^{\circ}$ to $90^{\circ}$ with a step size of $0.2^{\circ}$ and a collection time of $10 \mathrm{~s}$. All the specimens were polished and etched with $4 \%$ nital.

The macro-hardness measurement was done using an HR-150A-type Rockwell-hardness tester. The test load was $150 \mathrm{~kg}$. The micro-hardness of the matrix in Fe-Cr-B-Al alloy was measured using an HV-1000 digital display micro-Victorinox hardness tester with a load of $200 \mathrm{gf}$ and the time of $10 \mathrm{~s}$. Seven indentations were made on each sample under each experimental condition to check the reproducibility of the hardness data.

\subsection{Wear tests}

Wear tests were conducted in a conventional ring block abrasion testing machine (MM-200) for a load 


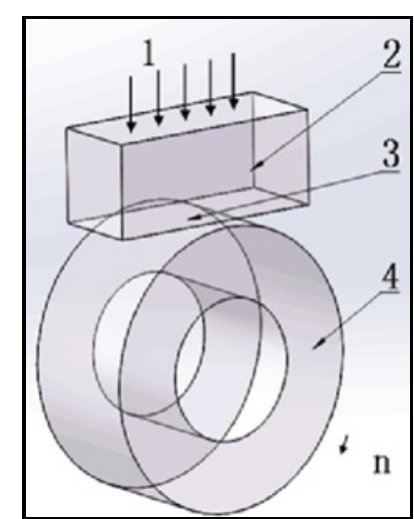

Fig. 1. Schematic of block-on-ring wear testing machine: 1 - load, 2 - specimen, 3 - ring-block contact surface, 4 grinding ring.

of $588 \mathrm{~N}$, a wheel rotation rate of $200 \mathrm{rpm}$, and a total of 6000 wheel revolutions. Figure 1 shows a schematic drawing of ring block abrasion testing machine. The specimen size was $10 \mathrm{~mm} \times 10 \mathrm{~mm} \times 15 \mathrm{~mm}$. The grinding ring material is GCr15, and its hardness and specifications are 60-62 HRC (after quenching) and $\varnothing 40 \mathrm{~mm} \times 10 \mathrm{~mm}$, respectively $[17,18]$. Its main chemical composition was 1.03 wt.\% C, 1.49 wt. $\%$ Cr, $0.35 \mathrm{wt} . \% \mathrm{Mn}$ and $0.27 \mathrm{wt} . \% \mathrm{Si}$. Before the experiment, all the specimens were cleaned with alcohol, and the mass of the specimens was measured gravimetrically with $0.1 \mathrm{mg}$ sensitivity. Then, they were assembled into the apparatus. Following a "running in" period, tests were conducted. After one running in the test, three tests were performed on each specimen. The results of wear tests were the average of three tests. The reciprocal of the weight loss represents the wear resistance of $\mathrm{Fe}-\mathrm{Cr}-\mathrm{B}-\mathrm{Al}$ alloy, and its unit is $\mathrm{mg}^{-1}$. The weight loss was measured by TG328B balance (sensitivity is $0.1 \mathrm{mg}$, and weighing range is $200 \mathrm{~g}$ ). The worn surface was observed by JSM6510 electron microscope with an EDS.

\section{Results and discussion}

\subsection{Effect of tempering temperature on microstructure of $\mathrm{Fe}-\mathrm{Cr}-\mathrm{B}-\mathrm{Al}$ alloy}

Figure 2 shows the X-ray diffraction pattern result, Fig. 3 represents the optical micrograph and scanning electron microstructure of Fe-Cr-B-Al alloy tempered at different temperatures. Figure 2 shows that the eutectic borocarbide is mainly composed of $\mathrm{M}_{7}(\mathrm{C}, \mathrm{B})_{3}$, $\mathrm{M}_{2}(\mathrm{~B}, \mathrm{C})$ and $\mathrm{M}_{23}(\mathrm{C}, \mathrm{B})_{6}$. Du Zhong-Ze et al. [19] also found that the eutectic borocarbide of $\mathrm{Fe}-\mathrm{Cr}-\mathrm{B}$ alloy included $\mathrm{M}_{7}(\mathrm{C}, \mathrm{B})_{3}, \mathrm{M}_{2}(\mathrm{~B}, \mathrm{C})$ and $\mathrm{M}_{23}(\mathrm{C}, \mathrm{B})_{6}$, it also can be seen that with the increasing tempering temperature, the type of eutectic phase did not change.

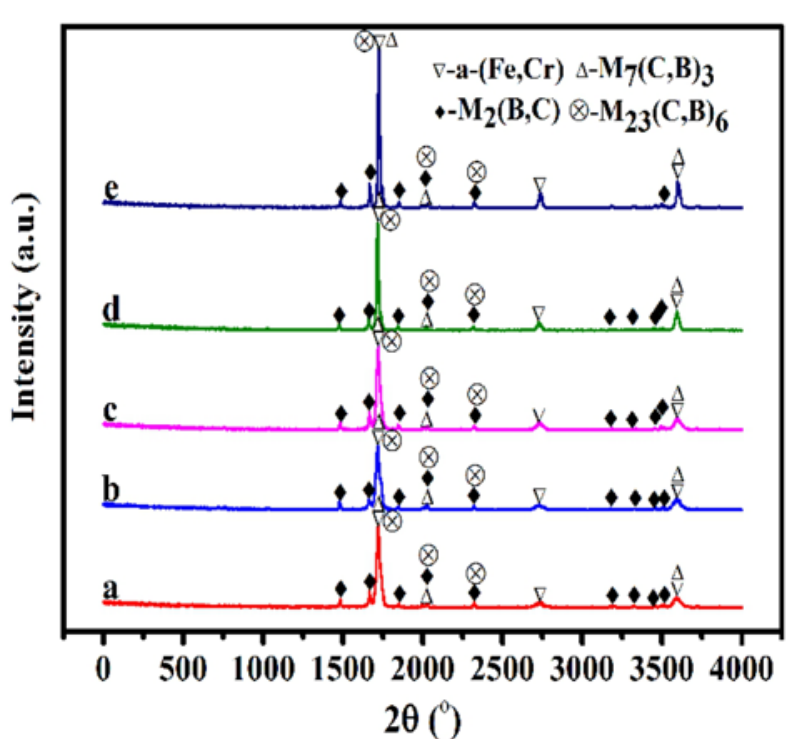

Fig. 2. The X-ray diffraction patterns of the samples with different tempering temperature: (a) $400^{\circ} \mathrm{C}$, (b) $450{ }^{\circ} \mathrm{C}$, (c) $500{ }^{\circ} \mathrm{C}$, (d) $550{ }^{\circ} \mathrm{C}$, and (e) $600^{\circ} \mathrm{C}$.

From Fig. 3, it can be seen that the microstructure of Fe-Cr-B-Al alloy is composed of tempered martensite, massive ferrite and discontinuous eutectic borocarbide after tempering. Figure $3 \mathrm{~b}$ shows that the tempered martensite is acicular. With the increasing tempering temperature, the retained austenite gradually transforms to martensite in the cooling process, which makes the alloy steel harden [20]. The microstructure of matrix of Fe-Cr-B-Al alloy tempered at $500^{\circ} \mathrm{C}$ is still tempered martensite. There is a certain dislocation density in martensite because of the rapid cooling, at the same time, the martensite breaks down in the process of heating due to the presence of various interfaces in it $[21,22]$. Therefore, with increasing tempering temperature, the massive ferrite in Fe-Cr-B-Al alloy has a tendency to become larger and larger.

\subsection{Effect of tempering on the hardness of $\mathrm{Fe}-\mathrm{Cr}-\mathrm{B}-\mathrm{Al}$ alloy}

The effect of tempering temperature on the hardness of Fe-Cr-B-Al alloy is shown in Fig. 4. The macrohardness has no significant change when the tempering temperature is lower than $450^{\circ} \mathrm{C}$. But the macrohardness of Fe-Cr-B-Al alloy decreases significantly when the tempering temperature is more than $450^{\circ} \mathrm{C}$ and reaches $43.0 \mathrm{HRC}$ while tempering at $600^{\circ} \mathrm{C}$. The effect of tempering temperature on the micro-hardness of matrix was basically consistent with the trend of the change of macro-hardness. When the tempering temperature is lower than $400^{\circ} \mathrm{C}$, the matrix which still retains a high hardness is tempered martensite. The atomic diffusion coefficient of instability marten- 

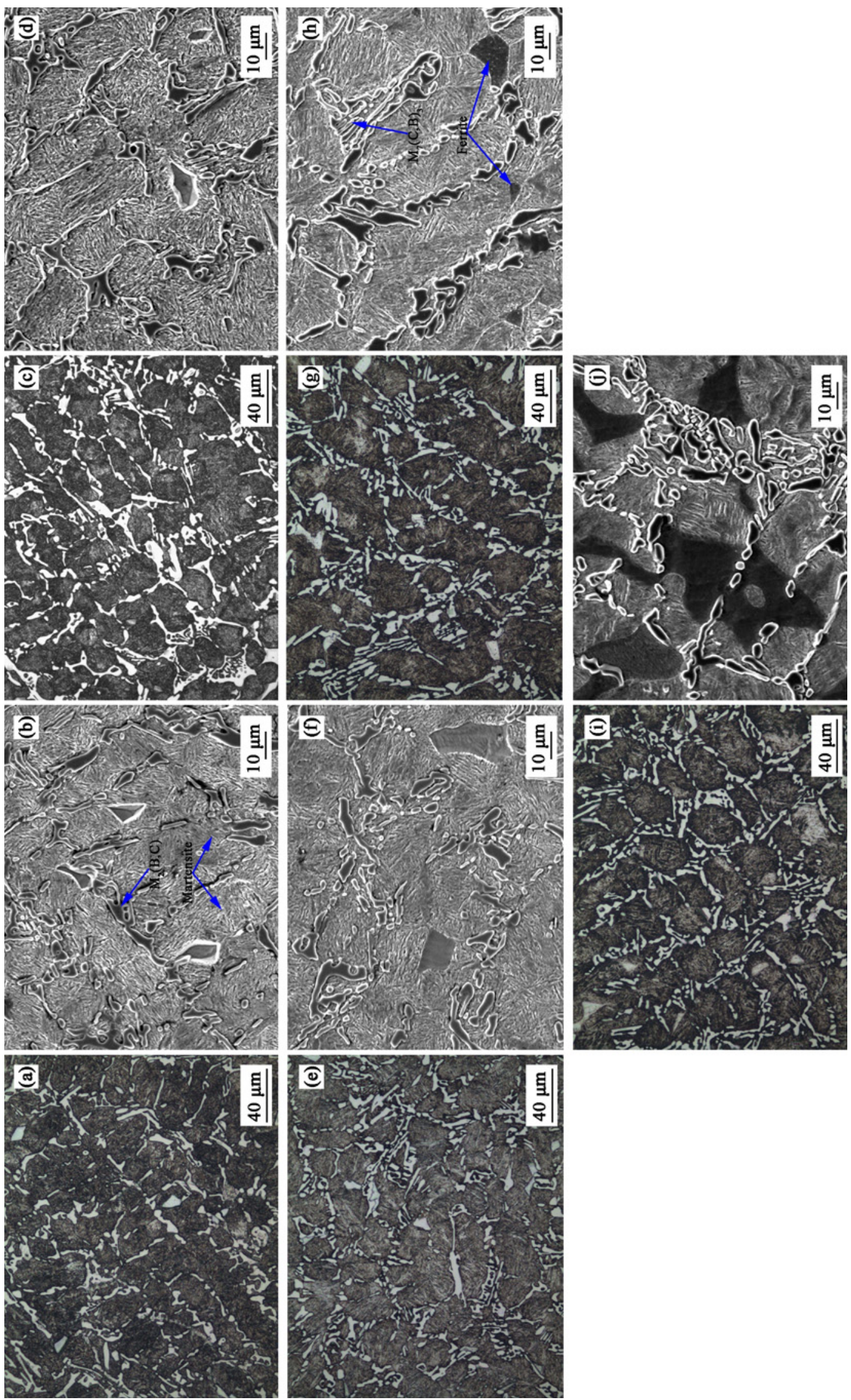

Fig. 3. Effect of tempering temperature on the microstructure of Fe-Cr-B-Al alloy: (a, b) $400^{\circ} \mathrm{C},(\mathrm{c}, \mathrm{d}) 450^{\circ} \mathrm{C},(\mathrm{e}, \mathrm{f}) 500^{\circ} \mathrm{C}$, $(\mathrm{g}, \mathrm{h}) 550^{\circ} \mathrm{C}$, and $(\mathrm{i}, \mathrm{j}) 600^{\circ} \mathrm{C}$. 


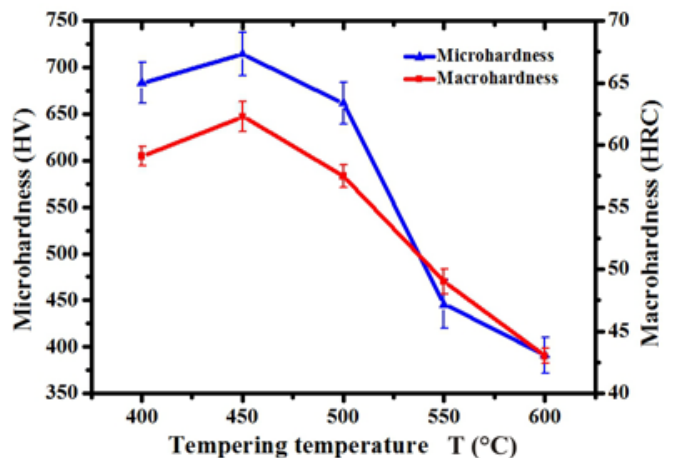

Fig. 4. Effect of tempering temperature on the macrohardness and micro-hardness of Fe-Cr-B-Al alloy.

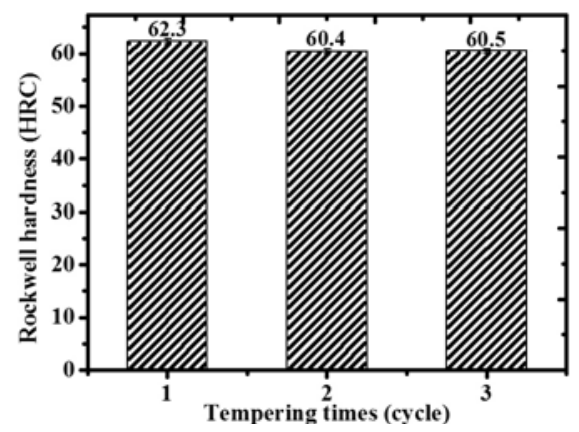

Fig. 5. Effect of tempering cycles on the Rockwell hardness of $\mathrm{Fe}-\mathrm{Cr}-\mathrm{B}-\mathrm{Al}$ alloy.

site produced during the quenching process increases at low tempering temperature. The saturated carbon element is gradually precipitated as carbide, and the crystal lattice distortion is reduced, and the microstructure containing martensite with a lower degree of saturation and very fine borocarbide is formed. The degree of supersaturation of martensite decreases with the increase of the tempering temperature, and the precipitation of borocarbide is gradually increased until the formation of tempered troostite that the carbide distributes on the ferrite. When tempered troostite is formed, internal stress gradually releases, the hardness also significantly decreases. Secondly, the borocarbides gather and grow up when the tempering temperature is too high, which makes the hardness drop.

The effect of tempering cycles on the hardness of Fe-Cr-B-Al alloy is shown in Fig. 5. The hardness of the alloy almost reaches the highest value after once tempering and decreases slightly after tempering for two or three cycles. This is mainly because after two or three cycles tempering, the borocarbides precipitated in the martensite gradually gather and grow up (as shown in Fig. 6), so the hardness is lower. The amount of carbon and alloying elements dissolved in the austenite is less. The stability of retained austen-
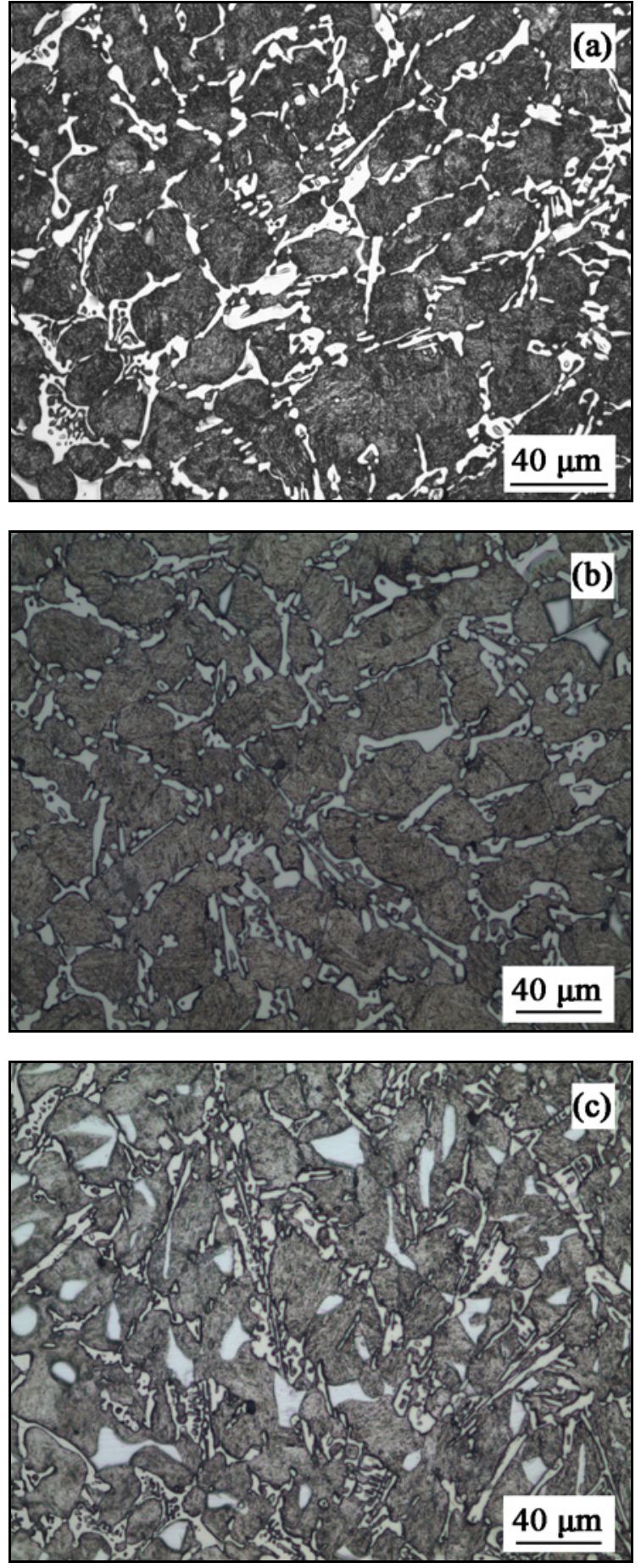

Fig. 6. Metallographic pictures of Fe-Cr-B-Al alloy tempered at $450{ }^{\circ} \mathrm{C}$ in different tempering times: (a) once, (b) twice, and (c) three times.

ite in quenched microstructure is poor. The quenching residual austenite almost completely decomposed after one-time temper. At the same time, the hardening of the Fe-Cr-B-Al alloy is also basically completed [23].

The effect of tempering time on the hardness of Fe-Cr-B-Al alloy is shown in Fig. 7. A small amount 


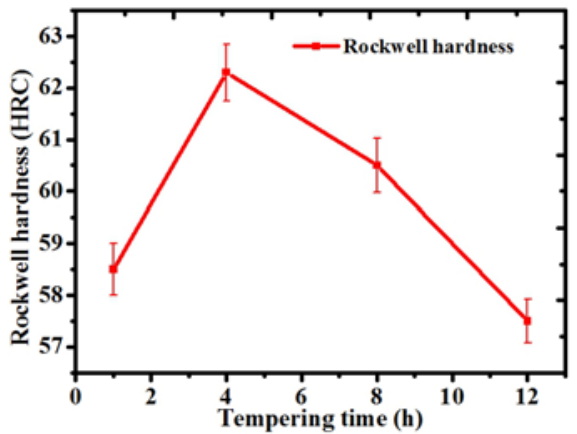

Fig. 7. Effect of tempering time on the Rockwell hardness of Fe-Cr-B-Al alloy.

of the secondary borocarbide is precipitated from the matrix when tempering time is too short, so the hardness is low. The extension of tempering time is beneficial to the precipitation of borocarbide, and the hardness of Fe-Cr-B-Al alloy increases gradually. However, when tempering time is too long, a large amount of secondary borocarbides is precipitated and coarsened, and there are many massive ferrites (as shown
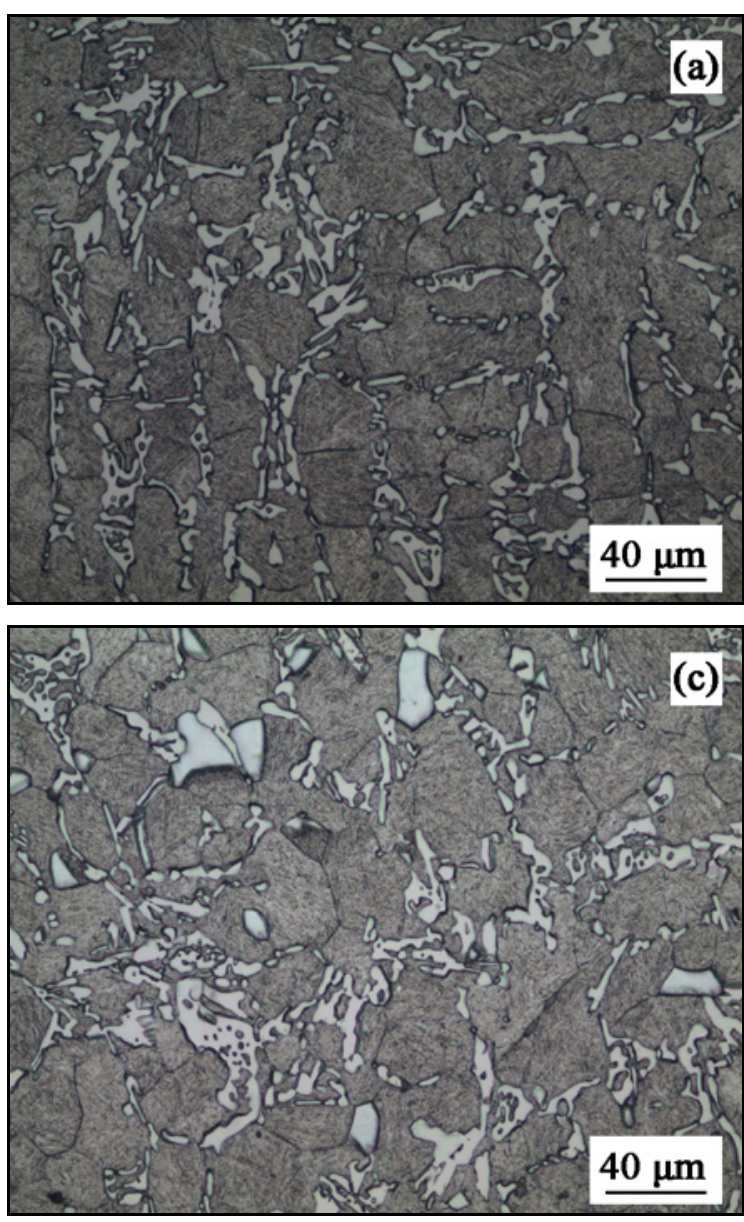

Fig. 8. Metallographic pictures of Fe-Cr-B-Al alloy tempered at $450{ }^{\circ} \mathrm{C}$ in different tempering times: (a) $1 \mathrm{~h}$, (b) $4 \mathrm{~h}$, (c) $8 \mathrm{~h}$, and (d) $12 \mathrm{~h}$.

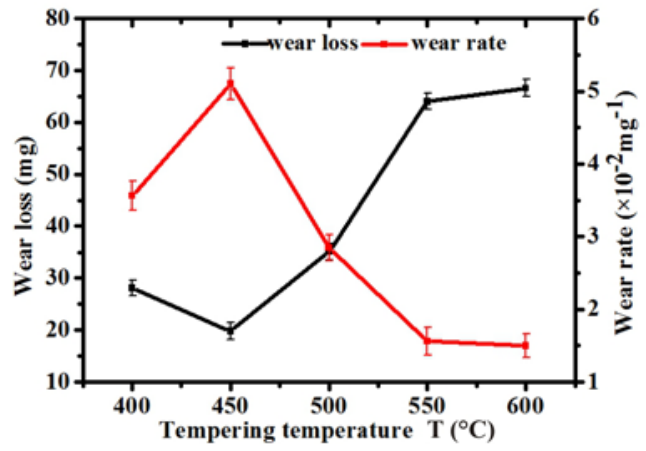

Fig. 9. Effect of tempering temperature on the wear resistance of Fe-Cr-B-Al alloy.

in Fig. 8), and the saturation of carbon and alloy elements in the matrix reduces, so the hardness of Fe-Cr-B-Al alloy begins to decrease.

\subsection{Effect of tempering on the wear resistance of $\mathrm{Fe}-\mathrm{Cr}-\mathrm{B}-\mathrm{Al}$ alloy}

Effect of tempering temperature on the wear re-
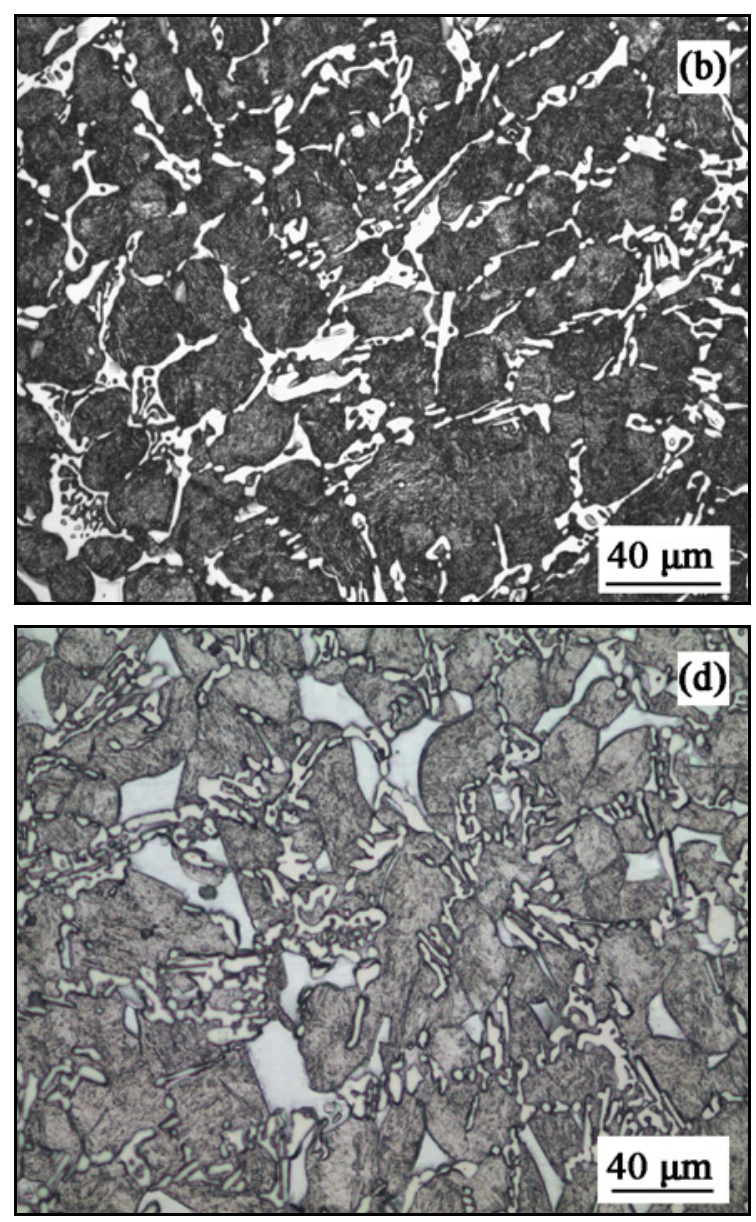

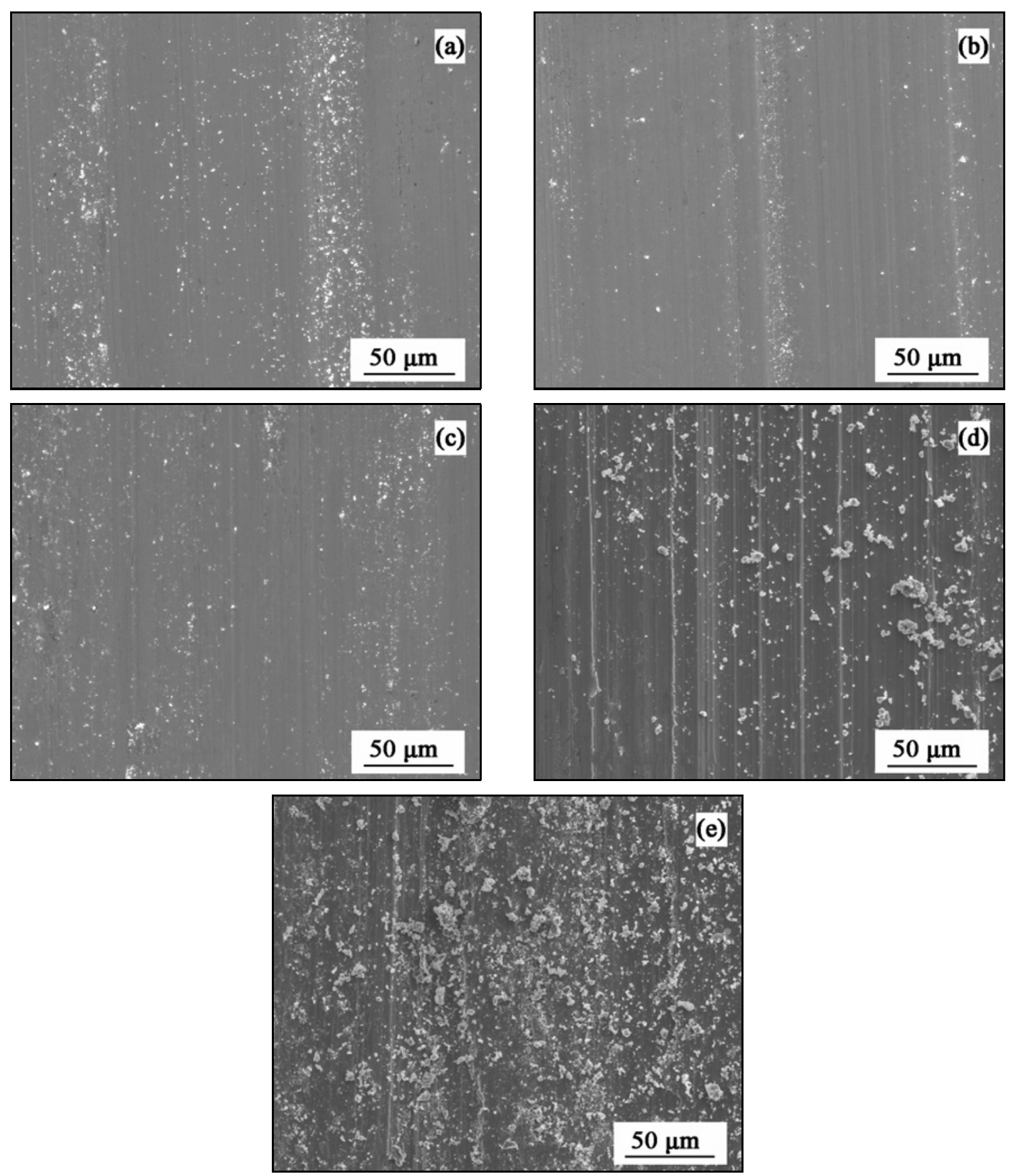

Fig. 10. Scanning electron microscopy images of worn surfaces tested at different tempering temperature: (a) $400{ }^{\circ} \mathrm{C},(\mathrm{b})$ $450{ }^{\circ} \mathrm{C}$, (c) $500{ }^{\circ} \mathrm{C}$, (d) $550^{\circ} \mathrm{C}$, and $(\mathrm{e}) 600^{\circ} \mathrm{C}$.

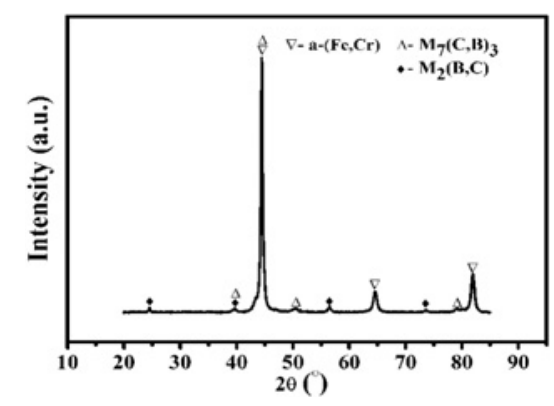

Fig. 11. X-ray diffraction pattern of the as-cast Fe-Cr-B-Al alloy. sistance of Fe-Cr-B-Al alloy is shown in Fig. 9. As the tempering temperature increases, the wear loss of the alloy reduces firstly and then increases. The corresponding abrasion resistance of $\mathrm{Fe}-\mathrm{Cr}-\mathrm{B}-\mathrm{Al}$ alloy is increased firstly and then decreased. To analyze the wear process and wear mechanism of Fe-Cr-B-Al alloy, the microstructures of worn surface of the samples are analyzed. Figure 10 represents the scanning electron microstructure image of the worn surface of $\mathrm{Fe}-\mathrm{Cr}-\mathrm{B}-$ -Al alloy tempered at different temperatures. It can be seen that the main wear mechanism is cutting wear and ploughing effect. The worn surface contains deep 

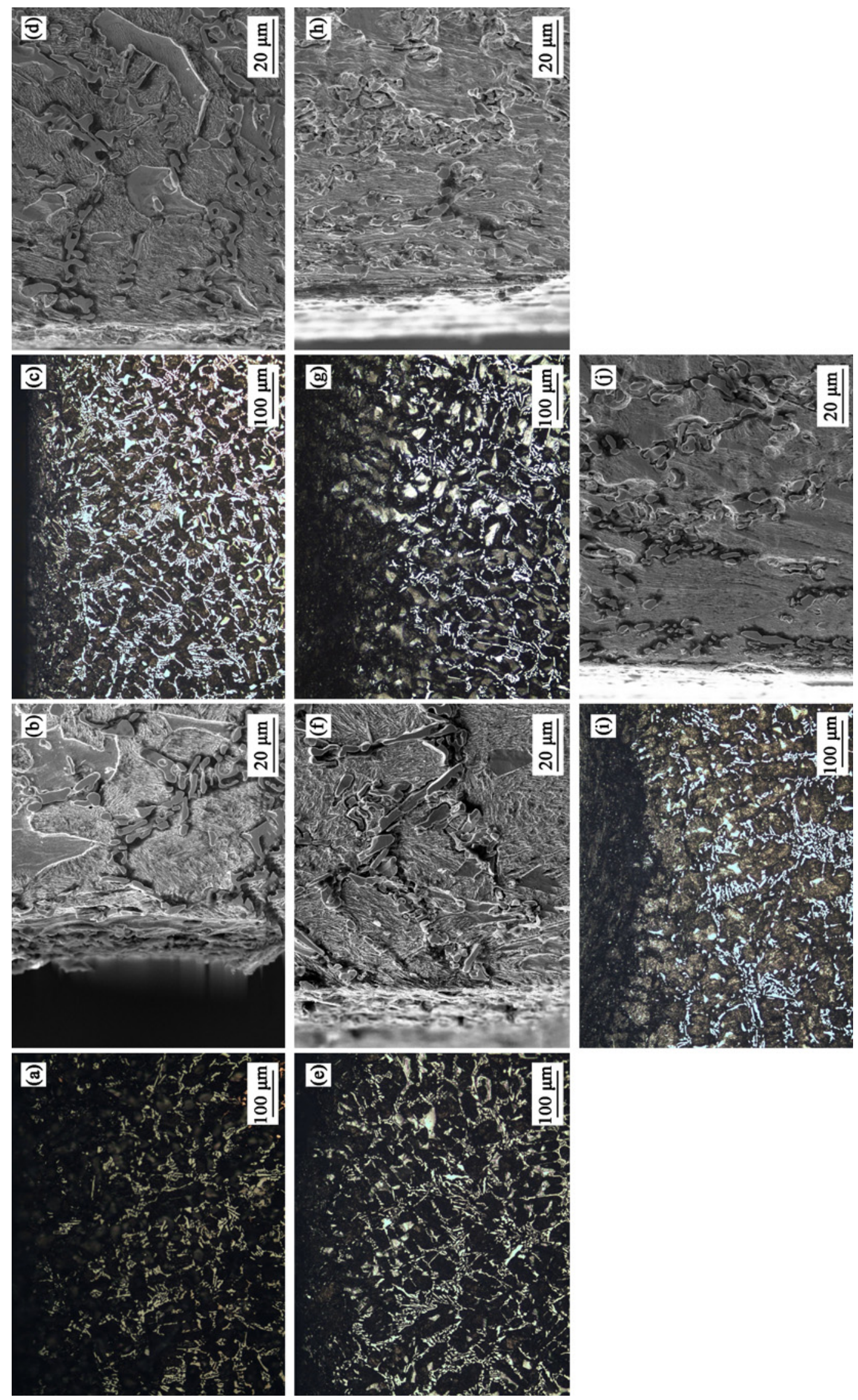

Fig. 12. The OM and SEM micrograph of a cross-section of scouring worn surface of the samples with different tempering temperature: (a, b) $400{ }^{\circ} \mathrm{C},(\mathrm{c}, \mathrm{d}) 450{ }^{\circ} \mathrm{C},(\mathrm{e}, \mathrm{f}) 500^{\circ} \mathrm{C},(\mathrm{g}, \mathrm{h}) 550{ }^{\circ} \mathrm{C}$, and $(\mathrm{i}, \mathrm{j}) 600^{\circ} \mathrm{C}$. 
and straight furrow and a large amount of wear debris. Moreover, the higher the tempering temperature, the more the number of wear debris is on the worn surface. Borocarbides in Fe-Cr-B-Al alloy mainly contain $\mathrm{M}_{7}(\mathrm{C}, \mathrm{B})_{3}$ and $\mathrm{M}_{2}(\mathrm{~B}, \mathrm{C}$ ) - type borocarbide (as shown in Fig. 11) [24]. The hardness of the alloy increases after tempering at $450^{\circ} \mathrm{C}$. The high-hardness matrix can provide good support for borocarbide, which makes borocarbide difficult to fall off. The borocarbide can also provide a good protection to the matrix, which is beneficial to reduce the wear of the matrix because specimen and the grinding ring move along the spiral in the ring block wear. The particles of falling-off stab into the surface of the sample under the action of normal force and move under the action of tangential force, which makes the sample surface be cut and worn, forming a trench on the surface of the sample [25]. Due to the high-hardness matrix at $450^{\circ} \mathrm{C}$ tempering, the particles of falling-off are not easy to be stabbed under the same test load, so the Fe-Cr-B-Al alloys show excellent wear resistance.

The destruction of the structure on the subsurface layer often causes the wear. For this purpose, the normal section of the worn surface of Fe-Cr-B-Al alloy tempered at different temperature was observed, as shown in Fig. 12. It can be seen from Fig. 12 that the wearing end-face is flat, the hard phase and the matrix are cut along the direction of wear. Hard phase particles falling off are pressed into the surface of the specimen in the process of grinding because of the high-hardness grinding ring, which improves the plastic deformation degree of the sample surface. The indentation depth of solid phase has a great relationship with a hardness of the surface of the sample. The lower the hardness of surface is, the deeper the indentation. After being pressed, the plastic deformation of the surface is also larger. When hard phase particles and materials cut each other along the horizontal direction, some ploughing furrows are generated on the worn surface. Most of the metal in the furrows discharge from the trench by the rheological way and a small part by plastic deformation. If these hard phases enter into the material surface by way of the wedge, the solid phases present brittle fracture and fall off when the shear stress exceeds shear strength of the hard phase, which leads to producing primary abrasive dust. The formation of primary abrasive dust inevitably increases the wear loss. Figures $12 \mathrm{~b}, \mathrm{c}$ represent the sub-surface area of sample tempered at $450^{\circ} \mathrm{C}$. It can be seen that borocarbide fragmentation degree is relatively small. Moreover, Fig. 4 shows that at this time the matrix has the highest hardness, the matrix itself has a high wear resistance, which provides effective support and protection for borocarbides. In turn, to a certain extent, the borocarbides form the anti-friction fulcrum, which protects the matrix.

\section{Conclusions}

1. The microstructure of tempered Fe-Cr-B-Al alloy consists of tempered martensite, massive ferrite and discontinuous eutectic borocarbide, and the eutectic borocarbide is mainly composed of $\mathrm{M}_{7}(\mathrm{C}, \mathrm{B})_{3}$, $\mathrm{M}_{2}(\mathrm{~B}, \mathrm{C})$ and $\mathrm{M}_{23}(\mathrm{C}, \mathrm{B})_{6}$. With increasing tempering temperature, the amount of retained austenite decreases and the amount of ferrite increases.

2. When the tempering temperature is lower than $450^{\circ} \mathrm{C}$, the hardness of Fe-Cr-B-Al alloy has no obvious change. As the temperature increases, the hardness gradually decreases. The hardness of the alloy almost reaches the highest value after once tempering and decreases slightly after tempering for two or three cycles.

3 . With the extension of tempering time, it is beneficial to the precipitation of borocarbide, and the hardness of Fe-Cr-B-Al alloy increases gradually. When the tempering time is too long, the hardness begins to decrease.

4. The main wear mechanism is cutting wear and ploughing effect. Fe-Cr-B-Al alloy has excellent wear resistance while quenching at $1100^{\circ} \mathrm{C}$ and tempering at $450^{\circ} \mathrm{C}$.

\section{Acknowledgements}

The authors appreciate the financial support for this work from the Natural Science Foundation of China under Grants No 51475005 and No 51274016.

\section{References}

[1] Echsler, H., Hattendorf, H., Singheiser, L., Quadakkers, W. J.: Mater. Corros., 57, 2006, p. 115. doi:10.1002/maco.200503897

[2] Zhang, Z. G., Gesmundo, F., Hou, P. Y., Niu, Y.: Corros. Sci., 48, 2006, p. 741. doi:10.1016/j.corsci.2005.01.012

[3] Niu, Y., Wang, S., Gao, F., Zhang, Z. G., Gesmundo, F.: Corros. Sci., 50, 2008, p. 345. doi:10.1016/j.corsci.2007.06.019

[4] Airiskallio, E., Nurmi, E. E., Heinonen, M. H., Väyrynen, I. J., Kokko, K., Ropo, M., Punkkinen, M. P. J., Pitkänen, H., Alatalo, M., Kollár, J., Johansson, B., Vitos, L.: Corros. Sci., 52, 2010, p. 3394. doi:10.1016/j.corsci.2010.06.019

[5] Christodoulou, P., Calos, N.: Mater. Sci. Eng., 301, 2001, p. 103. doi:10.1016/S0921-5093(00)01808-6

[6] Guo, C. Q., Kelly, P. M.: Mater. Sci. Eng. A, 352, 2003, p. 40. doi:10.1016/S0921-5093(02)00449-5

[7] Yu, Z., Fu, H. G., Jiang, Y., Cen, Q., Lei, Y., Zhou, R., Guo, H.: Mat.-Wiss. u. Werkstofftech., 43, 2012, p. 1080. doi:10.1002/mawe.201200058

[8] Zhou, X. F., Yin, X. Y., Fang, F., Jiang, J. Q.: Adv. Mater. Res., 217-218, 2011, p. 463. doi:10.4028/www.scientific.net/AMR.217-218.457 
[9] Yi, D. W., Xing, D. J., Fu, H. G., Ma, S. Q., Liu, Z. X.: Mater. Sci. Technol., 26, 2010, p. 849. doi:10.1179/026708309x12454008169302

[10] Dogan, O. N., Hawk, J. A.: Wear, 189, 1995, p. 136. doi:10.1016/ 0043-1648 (95)06682-9

[11] Smith, W. F., Hashemi, J.: Foundations of Materials Science and Engineering. New York, McGraw-Hill Science 2009.

[12] Luo, X. X., Yao, Z. J., Zhang, P. Z., Zhou, K. Y., Wang, Z. Z.: J. Mater. Eng. Perform., 25, 2016, p. 3938. doi:10.1007/s11665-016-2235-9

[13] Pokhmurs'ka, H., Chervins'ka, N., Student, M., Zadorozhna, Kh.: Mater. Sci., 42, 2006, p. 837. doi:10.1007/s11003-006-0152-z

[14] Student, M., Dzioba, Y., Hvozdets'kyi, V., Pokhmurs'ka, H., Wielage, B., Grund, T.: Mater. Sci., 44, 2008, p. 693. doi:10.1007/s11003-009-9131-5

[15] Cui, G. J., Kou, Z. M.: J. Alloys. Compd., 586, 2014, p. 699. doi:10.1016/j.jallcom.2013.10.110

[16] Sorour, A. A., Strauss, H. W., Chromik, R. R., Brochu, M.: Tribol. Lett., 44, 2011, p. 269. doi:10.1007/s11249-011-9845-Z

[17] Luo, X. X., Yao, Z. J., Zhang, P. Z., Chen, Y., Yang, H. Q., Wu, X. F., Zhang, Z. L., Lin, Y. H., Xu, S. J.: Trans. Nonferrous Met. Soc. China, 25, 2015, p. 3694. doi:10.1016/S1003-6326(15)64010-9
[18] Wang, J., Yan, F., Xue, Q.: Tribol. Lett., 35, 2009, p. 85. doi:10.1007/s11249-009-9435-5

[19] Du, Z. Z., Li, Y., Fu, H. G., Liu, F., Zhang, H.: Trans. Mater. Heat Treat., 35, 2014, p. 50. doi:10.13289/j.issn.1009-6264.2014.s2.011

[20] Dobrzański. L. A., Kasprzak, W.: J. Mater. Process. Technol., 109, 2001, p. 52. doi:10.1016/S0924-0136(00)00775-5

[21] Xu, S. L., Li, L. F., Yang, W. Y., Sun, Z. Q.: J. Univ. Sci. Technol. Beijing, 29, 2007, p. 901. doi:10.13374/i.issn1001-053x.2007.09.032

[22] Furuhara, T., Kobayashi, K., Maki, T.: ISIJ Int., 44, 2004, p. 1937. doi:10.2355/isijinternational.44.1937

[23] Yang, J., Fu, H. G., Du, Z. Z.: Trans. Mater. Heat Treat., 27, 2006, p. 54 . doi:10.13289/i .issn.1009-6264.2006.02.014

[24] Lv, Z., Fu, H. G., Xing, J. D., Ma, S. Q., Hu, Y.: J. Alloys Compd., 662, 2016, p. 54. doi:10.1016/j.jallcom.2015.11.171

[25] Du, Z. Z., Fu, H. G., Feng, Z. J., Li, P., Dai, J. F.: Trans. Mater. Heat Treat., 32, 2011, p. 93. doi:10.13289/j.issn.1009-6264.2011.02.019 